through an abdominal incision. Further, I think it must be granted that in each of the six cases the patient's hope of "cure" would have been nil had the glands been allowed to remain and that although in only two cases has the five years' limit been well passed and in two others almost, but not quite, reached, still, not one of these four would now be alive or have survived at the outside more than three years. In the two more recently done cases it must be allowed that they, at all events, have a fair chance of "cure" which otherwise would have been an impossibility. On reading the report of the Gynæcological Section at the last meeting of the British Medical Association in England, I saw that Professor Olshausen definitely condemned any other major operative procedure in carcinoma of the uterus than vaginal hysterectomy, stating also that it was impossible to know beforehand whether the pelvic glands were involved or not except, of course, in advanced and inoperable cases. This was used as an argument in favour of vaginal hysterectomy and against any more radical operation. Surely it ought to be the other way about. The few cases I have cited, and many more could be adduced, seem to prove this. Another argument used against the more thorough and radical operation was its great mortality, as stated by its critics. During the past six years I have found it to be only slightly-i.e., less than 1 per cent.-above the $3 \frac{1}{2}$ per cent. or 4 per cent. mortality assigned to the vaginal operation. When one is dealing with cancer such an added risk is justifiable if the prospect of "cure" is greater, and that this must be so I think the cases I have quoted proved.

I am aware that in taking up this position I am in opposition to all the speakers, with two exceptions, on the occasion referred to, but the facts seem to justify the position I have taken for the past ten years-i.e., in all cases of carcinoma of the uterus, where a major operation is justified, the only one admissible is that one which gives the greatest hope of "cure," provided that the primary mortality is not too great. To leave the pelvic glands behind in such cases is to jeopardise the patient's chances of "cure," small as they may be at best. I have not given a detailed account of the steps of the operation as I usually do it because I have already done so in the Journal of Obstetrics and Gyncecology of the British Empire for January, 1903.

Sydney, New South Wales.

\section{THE TECHNIQUE OF THE OPERATION FOR ADENOIDS AND ENLARGED TONSILS, WITH SOME PRACTICAL SUGGESTIONS.}

BY FREDERICK C. CARLE, M.B. LOND., M.R.C.S. ENG. SENIOR CLINICAL ASSISTANT TO THE THROAT HOSPITAL, GOLDENSQUARE, W.

THE operation for adenoid growths and enlarged tonsils, now so extensively practised, is in reality a more complicated surgical procedure than it appears to the casual observer. To perform the operation efficiently so as to obtain the greatest amount of benefit to the patient and satisfaction to the surgeon considerable skill is required which is only obtained by extensive practice. Many untoward aftereffects come before the surgeon's notice which he learns by experience how best to avoid. When one remembers that the completeness of the surgical measures employed is estimated by touch at the time of operation without directly viewing the area operated upon it will be readily appreciated that it is only by constant practice the surgeon is able to detect any incompleteness of his work by touch alone.

A description of the method of procedure as now practised at the Throat Hospital, Golden-square, will doubtless clear up many difficulties. The patient is anæsthetised with A.C.E. mixture on a flat table. Any pillow placed beneath the patient's head should be removed before the operation is commenced. The head thus maintains its normal relation to the trunk, upon which it is neither flexed nor extended. The importance of this I shall point out later. The degree of anæsthesia should be such that the conjunctival reflex is lost but not the reflex to light. A gag, preferably Doyen's, is now introdnced by the anxsthetist and the mouth well opened. The head is steadied by the anæesthetist. The surgeon, standing on the right side of his patient, introduces the forefinger of his left hand to depress the tongue, thus bringing into view the soft palate and uvvla StClair Thomson's adenoid curette is carefully passed behind the soft palate into the naso-pharynx. The handle of the curette is well depressed, so as to cause the cutting edge of the instrument to impinge against the base of the septum. The handle of the curette is carried through a semicircle, considerable pressure being used in making the cutting edge travel across the pharyngeal vault. In the latter part of the stroke so much pressure is not desirable for fear of cutting too deeply into the muscular tissue of the posterior pharyngeal wall. On withdrawing the instrument the mass of adenoid tissue is found in the cage of the instrument. The patient is immediately turned on to his right side, the nurse taking charge of the body and the anrsthetist of the head. The tonsils are next removed with a Heath's guillotine, the lower or right first. The surgeon defines the tonsil with his left forefinger, introduces the guillotine, and slips the ring over the organ. The handle of the instrument is carried well over to the opposite side, when the blade is pressed home and the tonsil removed. The upper or left is removed in a corresponding manner, the surgeon reversing his grasp of the handle in his right hand. The fauces and post-nasal space are then carefully palpated with the forefinger and any remaining adenoid tissue detected is removed with a Gottstein's curette. The violence of the bleeding is allowed to abate, when the patient is removed to bed in a prone position with the head low, a towel being held to the face during transit to catch any blood.

The practical points to which I would call attention are as follows. The horizontal position of the patient in the dorsal decubitus, the head being neither flexed nor extended. With the head extended the cervical curve of the spinal column is increased; in this position the operator is liable to cut deeply into the muscular structures of the posterios. pharyngeal wall, which will be stripped down by the curette, leaving extensive tags of muscle and mucous membrame These will slough and give rise to unpleasant symptoms in the after treatment, so making the patient more liable to acute middle-ear inflammation, a not infrequent result of the operation for adenoids. The lateral position favours the drainage of blood from the pharynx out through the month and in no way inconveniences the surgeon in removing the tonsils. In removing the tonsils a small guillotine is better than a large one, since the encircled organ is not so liable to slip out of the smaller ring. The lower end of the tonsil hangs down into the pharynx and does not merely project from between the faucial pillars. In removal, therefore, it is important to get the lower edge of the guillotine ring below this projection and to thread the ring on to the tonsil from below upwards. The posterior pharyngeal wall is best cleared at the end of the operation by scraping with the finger-nail from below upwards, thus avoiding tearing downwards of the posterior pharyngeal wall as is liable to follow the use of a curette. Large buried tonsils are best dealt with by removing a thin slice, followed by breaking down of the tonsil tissue with the finger. The cicatricial contraction following this method of procedure markedly reduces the size of the hypertrophied organ. The results obtained by the above method of operating are eminentlix; satisfactory, any after ill-effect rarely occurring.

William-street, S.W.

\section{ANATOMICAL PECULIARITIES OF \& GALL-BLADDER AND AN APPENDIX.}

BY FERGUSON LEMON, M.B., B.S. MELE.

AN instance of inclusion of a gall-bladder in the saib stance of the liver presented itself recently while Dr. W. K. Bouton of Melbourne was operating for gall stones. After opening the abdomen in the manner recommended by Mr. A. W. Mayo Robson for this kind of operation the liver presented itself in the operation wounc: and what appeared to be a hyclatid cyst was seen or the anterior surface of the right lobe-a slightly rounded elevation of pale jellowish colour. On lifting the liver forward a similar though somewhat more projecting eninence appeared on the posterior surface which when viewed through the substance of the liver was quite translucent. It was.ic 
the normal position for a gall-bladder but the surfaces, both anterior and posterior, were continuous with the liver substance. As no gall-bladder could be di-covered an incision was made on the posterior surface into the swelling when bile gushed out, and on further exploration two large gallstones, one barrel-shaped and the other conical, were secured ; there was an additional fucet on the barrel-shaped stone showing that a third stone had been presert, but as a probe passed the whole length of the common duct without striking one it had evidently been passed previculy. The ellge of the incision into the gall-bladder at the time of operation was at least three-eighths of an inch thick, the circularly arranged coat of the gall-bladder being marked off very definitely from the liver substance on the one hand and the mucosa, \&c., of the bladder on the other. Having secured a specimen for microscopical examination the usual procedure for closing the abdumen and draining the gall bladder was undertaken. On examination with the naked eye after the usual hardening process the specimen measured about three millimetres and showed the same three layers as already mentioned. Under low power the layers were made up of (1) an outer thick layer of connective tissue, probably a continuation of Glisson's capsule; (Z) a circularly arranged layer of connective tissue, evidently the true covering of the gall-bladder; and (3) the mucosa, muscular tissue, \&c., of the gall-bladder. The thickness of the anterior surface of the bladder and liver appeared to be slightly more than that of the posterior surface, but no section was made of it.

Curiously enough on the same day at another operation for appendicitis a divergence from the normal was scen in the appendix. On lifting the cæcum into view a small elevation on the anterior surface of the cæcum, about five inches from the extremity of the gut, was seen from which a little pus oozed. At first sight it looked like a perforation of the crecum itself, as no trace of the appendix connected with it could be seen, but on further examination a little loop of appendix with a diameter of half an inch sprang from the extremity of the gut and, passing upwards, appeared to end in the crecum half an inch away from its origin. No elevation appeared on the smooth peritoneal surface to indicate that the loop had any connexion with the perforated elevation four and a half inches distant. However, taking the loop as a guide and carefully dissecting away the peritoneum the appendix was traced till it ended in the elevation. The appendix was then stripped off the cæcum and removed in the ordinary manner. The exposed surface beneath was the muscular tissue of the cæcum and it bled freely. After careful application of a continuous suture of fine catgut through the free edges of the peritoneum, including some of the muscular layer, the bleeding was stopped, and for further security a secord row was inserted invaginating the first and including the stump of the appendix. The abdomen was then closed.

Both cases did excellently. I am indebted to Dr. Bouton for permission to publish them.

Hawthorn, Victoria, Australia.

\section{CASAREAN SECTION FOR CONGENITAL MALFORMATION OF THE CERVIX} UTERI ; RECOVERY.

By H. TRAILL SKAE, M.B., CH.B. ABERD., HONORARY DISTRICT SURGEON TO THE ROYAL MATERNITY CHARTTY.

THE patient, aged 24 years, married, pregnant for the first time, was taken in labour early on June 12th, 1904, being then seven and a half months pregnant. She was a wellbuilt, healthy woman. Her menstrual history was normal except that she sometimes had a good deal of pain. She was seen about 1 P.M. by a medical man of much experience who found an apparent absence of the cervix but did not interfere. At 9 P.M. he handed the patient into the care of my partner, Dr. W. D. G. Mulloy, who subsequently asked me to extmine her with a view to operation. The patient had then been in strong labour for about 12 hours and was becoming exhausted. The liquor amnii was stated to have been dribbling away all day. 'The patient was emphatic in saving that she had felt the child move a few hours before.

On examination at 10.30 P.M. pains were found to be frequent and sharp but of short duration. The patient was a well-formed woman with no abnormality of the bony pelvis. The fundus uteri was one and a half inches above the umbilicus (most of the liquor amnii had dribbled away). The fotal head could be felt above the pubes. The externa genitals were normal. The vagina was unusually short, the finger being brought to a standstill quite unexpectedly, and just for a moment the impression of total absence of a cervix was strikingly given. The vaginal walls were quite lax and undilated. On further examination it was found that the vaginal cervix was represented by a small flat warty projection, somewhat irregular and quite hard and firm. At its centre was the $0=-$ a small opening hardly large enough to admit a probe. This projection was placed almost in contact with the rectal wall, the posterior fornix being alinost unrepresented. A slimy purulent discharge was oozing from the opening. The foetal head could not be distinctly felt through the vagina. No fotal movements could be felt and the heart sounds were not to be heard. It was evident that there would be much difficulty in introducing any instrument to dilate the os and further, that any attempt to dilate would inevitably result in rupture into the rectum. And as it appeared advisable to sterilise the patient by tying and dividing the Fallopian tubes abdominal Cæsarean section was decided upon. (Permission to sterilise was, however, subsequently refused.) Sedatives were given to enable the patient to get some rest.

At 11 A.M. on the next day chloroform was administered by Dr. R. Purdie, the patient having been prepared in the usual way, and Dr. Mulloy assisted $m e$ in the operation. The abdomen and uterus were opened in the middle line, an elastic ligature being placed round the latter. This tourniquet had afterwards to be temporarily loosened as it was found to have caught the fœetal scalp; bleeding, however, was readily controlled with the hands. The foetus had evidently been dead for some days as putrefactive decomposition was well marked. The placenta, attached to the posterior wall of the uterus, was soft and foul-smelling-quite putrid. The uterus was emptied and scraped and then swabbed with perchloride solution ( 1 in 2000) followed by sterilised water. With considerable difficulty a narrow strip of gauze was forced into the vagina, about one and a half inches projecting into the uterus to act as a drain. The uterus was closed with deep and superficial sutures and contracted well The abdominal wall was sutured in one layer and dressed. Vaginal douches of izal were given twice daily. There was a little feverishne:s for some days owing to the imperfect drainage from the uterus. The gauze drain was expelled on the fifth day. The perchloride swabbing caused no illeffucts and the patient made a good recovery.

There was no history of any malformation in the patient's family.

Hampstead, N.W

\section{3itledical Soccietics.}

\section{ROYAL MEDICAL AND CHIRURGICAL SOCIETY.}

A Case of "Splenomegalic" or "Myelopathic" Polycythamia with Irue Plethora and Arterial Hypertonia, without Cyanosis.

A MEETING of this society was held on May 9th, Mr.

H. T. Butlin, Vice-President, being in the chair.

Dr. F. PARKES WeBer read a paper on a case of "Spleno megalic" or "Myelopathic" Polycythæmia with True Plethora and Arterial Hypertonia, without Cyanosis, which is published in full in this issue of THE LANCET.

Dr. J. S. HALDANE agreed that all facts pointed to an increase in the activity of the bone marrow as the cause of the polycythæmia. The method of determining the total volume of bluod by the carbon-monoxide method gave results which were identical with results obtained by older methods. $\mathrm{H}$ referred to the extraordinary constancy of the ratio of the hromoglobin and of the total blood volume to the body weight under various conditions. In the case under consideration, however, the blood volume was nearly double the normal ratio. The patient's condition was similar to that of an animal into which blood from another animal had been injected - there were an increase in the percentage of hæmoglobin and an enormous increase in the number of blood cells. 